\title{
NOVUS ACTUS AND BEYOND: ATTRIBUTING CAUSAL RESPONSIBILITY IN THE CRIMINAL COURTS
}

\author{
ANTJE DU BoIs-PEDAIN*
}

\begin{abstract}
Glanville Williams's influential 1989 article on causation, "Finis for Novus Actus?", addressed two pertinent questions: (1) when, and on what grounds, may a person be judged to bear causal responsibility for harms most immediately brought about by the subsequent action of another person (the locus classicus of the novus actus interveniens doctrine), and (2) how should questions of causation be resolved in cases where the potential cause in question constitutes an omission? This article revisits these questions through an engagement with some of the major causation cases decided in the criminal courts in the past decade. The discussion of these cases is set in the broader context of a critique of H.L.A. Hart and Tony Honoré's influential doctrinal-theoretical framework for findings of legal causation, the autonomy doctrine, on which Williams had built his arguments.
\end{abstract}

KEYWORDS: causal responsibility, factual causation, legal causation, novus actus interveniens, intended consequences and remoteness, autonomy doctrine, causation by omission, loss of a chance.

\section{INTRODUCTION}

"Finis for Novus Actus?" by Glanville Williams is one of the best-known articles to have appeared in the Cambridge Law Journal. ${ }^{1}$ Addressing the theory underpinning causation in criminal law through the prism of the draft clause on causation in the Law Commission's 1989 Draft Criminal Code, it has retained a place in the canon of criminal law teaching materials long after the Draft Code has been allowed to slip into oblivion. Its main themes remain as difficult and relevant today as they were back then: (1) when, and on what grounds, a person may be judged to bear causal responsibility $^{2}$ for harms most immediately brought about by the subsequent

* Faculty of Law, University of Cambridge. Address for Correspondence: Magdalene College, Cambridge, CB30AG, UK. Email: alp22@cam.ac.uk.

1 G. Williams, "Finis for Novus Actus?" [1989] C.L.J. 391.

${ }^{2}$ A finding of causal responsibility establishes that an event/outcome can be attributed to an agent as "his deed". In the traditional terminology of the criminal law, the causation analysis is split into two distinct steps referred to as "factual" and "legal" causation, with evaluative questions usually addressed under 
action of another person (the locus classicus of the novus actus interveniens doctrine), and (2) how questions of causation should be resolved in cases where the potential cause in question constitutes an omission.

Issues of causation exercised Glanville Williams in many of his other contributions to the Cambridge Law Journal as well. Most prominent among these are his extensive review article, "Causation in the Law", of the first edition of H.L.A. Hart and Tony Honoré's classic book of the same title, ${ }^{3}$ and his case note on Blaue. ${ }^{4}$ Williams adopted few theoretical commitments, but when he did so, he was quite prepared to castigate the courts for failing to adopt them in turn. ${ }^{5}$ Even so, his article on causation rests to an extent unusual for Williams on a specific theoretical premise, to wit: the "autonomy doctrine". ${ }^{6}$ This doctrine is encapsulated in the proposition that "[o]nly ... the final wielder of human autonomy in the matter, bears responsibility (along with his accomplices) for the result that ensues". ${ }^{7}$ This premise appears to rule out categorically the attribution of causal responsibility to an earlier agent for an outcome that was most immediately brought about by the responsible and informed agency of a later agent. As Williams also discusses, the very same limitation on the recognition as causal of influences over the fully responsible human agent closest to an outcome also generates a particular doctrinal-theoretical position on secondary liability. In this perspective, secondary liability is needed to selectively bridge a liability gap left by the absence of a causal link of the secondary party to the harmful outcome (the principal's crime). The bridge is selective in that not any influence of the more remote actor over the immediate actor can cross it but only those influences that amount to secondary participation (aiding, abetting, counselling, or procuring). ${ }^{8}$

Williams stresses that the autonomy doctrine is not "a scientific theory about the universe", since it is obvious that "[h]uman behaviour can be, and is, studied as the subject of causal influences". ${ }^{9}$ Moreover, he concedes that such causal explanations of human behaviour can appropriately be taken into account in sentencing decisions. But he insists that the autonomy doctrine must govern responsibility-attributions, where:

\footnotetext{
the heading of legal causation. Although I occasionally use the traditional expressions "factual" and "legal" causation in the text, I often prefer to speak simply of "causal responsibility" or "causal responsibility-attribution" as an umbrella term for the enquiry that needs to be performed. In my view it is often not possible to keep factual and normatively evaluative questions fully separate from each other in the context of this enquiry. They are to some extent amalgamated - particularly, but not only, in the context of causation by omission.

3 G. Williams, "Causation in the Law" [1961] C.L.J. 62, reviewing H.L.A. Hart and A.M. Honoré, Causation in the Law, 1st ed., (Oxford 1959). A second edition was published in 1985.

4 G. Williams, "Criminal Law - Causation" [1976] C.L.J. 15, commenting upon Blaue [1975] 1 W.L.R. 1411. See note 21 below for details on this case.

5 E.g. his commitment to subjective fault.

6 Williams, "Finis", 393.

7 Ibid., at 392 .

8 Ibid., at 394, 397-98.

9 Ibid., at 392
} 
[E]xpressing itself through its corollary the doctrine of novus actus interveniens, [it] teaches that the individual's will is the autonomous (self-regulating) prime cause of his behaviour. ... The first actor who starts on a ... criminal plan will often be responsible for what happens if no-one else intervenes, but a subsequent actor who has reached responsible years, is of sound mind, has full knowledge of what he is doing, and is not acting under intimidation or other pressure or stress resulting from the defendant's conduct, replaces him as the responsible actor ... break[ing] the moral connection that would otherwise have been perceived between the defendant's acts and the forbidden consequence. ${ }^{10}$

The theoretical positions Williams adopted were defended by the leading theorists of the time, giants in their respective fields: Hart and Honore on causation, ${ }^{11}$ and Kadish on complicity. ${ }^{12}$ But even at the time, these positions were difficult to reconcile with some of the decided cases, and the theoretical superstructure erected through their adoption was, and remains, open to challenge. It is, for instance, quite possible to interpret the influence exerted by the secondary party's contribution over the principal's crime as causal without thereby giving up on the special character of secondary participation. In another publication, I have argued that a causal link is perfectly compatible with (and, indeed, in a looser "contributory influence" sense, a component of) complicitous responsibility. ${ }^{13}$ The real significance of the rules of secondary liability then consists, not in the creation of a connection of the secondary party to a criminal harm that would otherwise be lacking, but in the modification, specification (and, to some extent, limitation) of responsibility-attribution to those labelled secondary parties in the factual situations to which complicity rules apply. ${ }^{14}$ Consequently, the patterns and requirements of secondary participation displace, as normative regimes for responsibility-attribution, general causation-based responsibility-attribution. But it remains an open question - not prejudged by the existence of a separate regime of responsibility-attribution to secondary parties - whether other influences by one agent over the conduct of another agent (for instance, enabling this other agent's harmful behaviour,

10 Ibid., at 392 .

11 Hart and Honoré, Causation.

12 S.H. Kadish, "Complicity, Cause and Blame: A Study in the Interpretation of Doctrine" (1985) 73 California Law Review 323.

13 A. du Bois-Pedain, "Complicity" in L. Alexander and K.K. Ferzan (eds.), The Palgrave Handbook of Applied Ethics and the Criminal Law (London 2020), ch. 9. The reason I deny that responsibility for complicity is reducible to responsibility based on causation is that causality is an insufficiently nuanced basis for responsibility-ascription in these cases. While (if interpreted broadly) it identifies a workable prerequisite of responsibility-ascription for the crimes of others qua "results" of one's own behaviour, it does not as such identify the distinctive ethical basis on which the secondary party shares moral responsibility for the principal's acts or acquires moral responsibility for the principal's crime.

14 It is no counterargument to this to point out that secondary liability is derivative in the sense that it depends on the performance of the conduct element of an offence by the principal. Without occurrence of the criminal harm, which is what the conduct of the principal brings about, the influence exercised by the secondary party would not have matured into criminal harm. That the act by the principal is necessary to complete the causal sequence does not mean that the end-result is not causally connected also to the conduct of the secondary party. 
or manipulating him into self-harming or into harming others) can give rise to causal responsibility of the first agent.

In this article, I will pursue this open question further and take issue with the approach that makes the answer turn exclusively on the question whether a causal sequence was "interrupted" (a term I use only in a figurative sense here) by someone who acts in a manner that is "free, deliberate and informed". Drawing on the philosopher Joel Feinberg's criticism of the perspective on human agency that informs the autonomy doctrine, I will develop a different framework for when and why causal responsibilityattribution to an earlier actor for consequences most immediately brought about by a subsequent actor should occur. This framework is, I contend, better able to explain the decisions the courts have reached and offers better guidance to the courts in future cases. It also helps us understand that the evaluative exercise involved in findings of legal causation (or imputation, as Continental lawyers would say) involves attention to a range of factors. This, in turn, allows us to understand why courts generally require foreseeability of consequences but nevertheless attribute causal responsibility when the consequence, albeit reached by an unforeseeable turn of events, was intended. It also makes room for additional principles that limit responsibility-ascription quite independently from novus actus considerations. One such broader principle of causation emerges from the Supreme Court's judgment in Hughes ${ }^{15}$ - a principle that ensures that causal responsibility is only attributed to defendants when their conduct concretely gave rise to the kinds of risks that the prohibition they have breached is abstractly trying to prevent. Lastly, I revisit the issue of causation by omission and explore the case for lowering the evidential bar (to some degree of probability less than practical certainty), and/or choosing a different evidential target ("proven increase of risk", "proven loss of a chance") in omissions cases.

\section{ENTER NOVUS ACTUS}

The novus actus interveniens doctrine, already invoked on two previous occasions, ${ }^{16}$ was endorsed in ringing tones by the House of Lords in Kennedy (no 2), where Lord Bingham's leading speech cited both Williams's article, and Hart and Honoré's book, as providing "classic statements" of the "fundamental and not controversial" principle that "informed adults of sound mind are [to be] treated as autonomous beings able to make their own decisions how they will act", such that " $\mathrm{D}$ is not to be treated as causing $\mathrm{V}$ to act in a certain way if $\mathrm{V}$ makes a voluntary and informed

15 Hughes [2013] UKSC 56, [2013] 1 W.L.R. 2461, discussed in Section IV below.

${ }^{16}$ Pagett (1983) 76 Cr.App.R. 279 (C.A.), 288-90 and Latif [1996] 1 W.L.R. 104 (H.L.). 
decision to act in that way rather than another" ${ }^{17}$ From Williams's article, Lord Bingham took the notion that "[V's] volitional act is regarded (within the doctrine of responsibility) as setting a new 'chain of causation' going, irrespective of what has happened before", 18 and from Hart and Honoré's book, the proposition that " $[\mathrm{t}]$ he free, deliberate, and informed intervention of a second person, who intends to exploit the situation created by the first, but is not acting in concert with him, is normally held to relieve the first actor of criminal responsibility". ${ }^{19}$

The "free, deliberate and informed intervention (FDI)" formula for what constitutes a novus actus interveniens has, however, always had an uneasy fit with the facts of the decided cases at best. If we focus our attention on the question whether a later agent's conduct is "free, deliberate and informed", it can only appear odd that (as in Roberts) the "daftness" of a victim's reaction to the defendant's action should be indicative of a causal break, ${ }^{20}$ while (as in Blaue) a carefully considered, religiously motivated refusal to receive a life-saving blood transfusion should constitute no such thing. ${ }^{21}$ Of course, in both these cases the courts have said that their judgment turns merely on whether the victim's reaction was foreseeable - but that in itself is problematic, if the autonomy doctrine is taken to be of general application. In terms of consistency, it also raises questions as to why these victims' conduct should not be assessed under the novus actus interveniens principle, given that the victim's conduct in Kennedy (no 2) clearly was. Perhaps the difference was that, in Kennedy (no 2), D had not placed the victim in a position where he was forced to react in some way or another - either by submitting to D's unwanted advances, as in

${ }^{17}$ Kennedy (no. 2) [2007] UKHL 38, [2008] 1 A.C. 269, at [14]. In this case, the defendant (D), who lived in the same hostel as the victim (V), had at V's request prepared a syringe with heroin for $\mathrm{V}$ which $\mathrm{V}$ had then self-injected. D had already gone back to his own room when V stopped breathing. An ambulance was called but upon arriving at the hospital $\mathrm{V}$ was found to have suffocated on his own vomit while acutely intoxicated by opiates and alcohol. On a reference by the Criminal Cases Review Commission, D's appeal against his conviction for manslaughter succeeded.

18 Kennedy (no. 2), [2007] UKHL 38, at [14], citing Williams, "Finis", 392.

19 Kennedy (no. 2), [2007] UKHL 38, at [14], citing Hart and Honoré, Causation, 2nd ed., 326. When referring to the same principle in the context of tort law, Hart and Honore use the phrase "free, deliberate and informed act or omission" (at 136), which clarifies that - contrary to Williams's opposite contention in "Finis", 392 - the principle applies as much to omissions (in breach of duty) as it does to acts. See also D. Klimchuk, "Causation, Thin Skulls and Equality" (1998) 11 Canadian Journal of Law and Jurisprudence 115, 126.

20 In Roberts (1971) 56 Cr.App.R. 95 (C.A.), a young woman (V) had accepted a lift by another party guest (D). When $\mathrm{D}$ told $\mathrm{V}$ to undress and grabbed at her clothes while driving, she opened the passenger door and jumped out, injuring herself. D was convicted of assault occasioning actual bodily harm. Rejecting his appeal, the court held that "if ... the victim does something so 'daft', in the words of the appellant in this case, ... that no reasonable man could have foreseen it, then it is only in a very remote and unreal sense a consequence of his assault, it is really occasioned by a voluntary act on the part of the victim which could not reasonably be foreseen and which breaks the chain of causation ..." (at 108 (Stephenson L.J.)) - a threshold which the reaction of V in this case had not crossed.

21 In Blaue [1975] 1 W.L.R. 1411 (C.A.), D had entered V's house and stabbed her repeatedly with a knife, one of the stabs piercing her lung. V was a Jehovah's witness and, when she was told that she could only survive with surgery after a blood transfusion, she refused to receive the blood transfusion. $\mathrm{V}$ died soon thereafter. The prosecution accepted that $\mathrm{V}$ would have survived, had she accepted the treatment. D's appeal against conviction for manslaughter failed. 
Roberts, or by permitting medical treatment, as in Blaue. ${ }^{22}$ In Kennedy (no 2), by contrast, the victim could have decided not to self-inject; the defendant put no pressure whatsoever on him to do so. Perhaps this was indeed the reason why the judgment in Kennedy (no 2) made the concept relevant when the judgments in Blaue and Roberts did not, but even so, to find the victim in Kennedy (no 2) - a drug addict craving his next fix - held up as a prime specimen of "free, deliberate and informed" agency will appear no less strange to the ordinary person than to the philosopher, for whom the addict reaching for his drug constitutes a paradigm example of unfree agency (a "wanton" controlled by his desires who just cannot muster the willpower to resist the temptation to take the $\operatorname{drug}^{23}$ ).

The logic of novus actus appears even more challenged in cases where the later actor's conduct is denied the effect of "breaking" the causal chain but concurrently treated as giving rise to legal liability (civil or even criminal) in its own right. No amount of fancy footwork can convert the fatal shot of a police officer firing at a suspect who is holding a human shield in front of him ${ }^{24}$ - conduct sufficiently voluntary and culpable to give rise to civil liability for negligently killing the human shield - into an act that is in any plausible sense unfree, non-deliberate, or uninformed. ${ }^{25}$ The same puzzling co-existence of perfectly responsible agency from the perspective of civil litigation, but the denial that such agency constituted "free, deliberate and informed" conduct for the application of the novus actus principle in criminal law, also regularly arises when the potential intervening cause constitutes negligent medical treatment. ${ }^{26}$ Here it is moreover (in obvious tension with the philosophical edifice on which the whole analysis rests) accepted that the later agent, whose negligent treatment most directly causes the criminal harm, does remain in the picture

22 It is sometimes suggested that Blaue might be explained by the fact that the victim's treatment refusal does not introduce a further physical-mechanical causal factor into the situation. But this is not the reason why the court refrains from analysing the treatment refusal as a potential novus actus interveniens. Rather, the court analogises the victim's beliefs, and their consequences for her decisions, to other preexisting conditions from which V may suffer and (at $1415 \mathrm{G}-\mathrm{H}$ ) applies the principle that D "must take his victim as he finds him".

23 H. Frankfurt, "Freedom of the Will and the Concept of a Person" (1971) 68 Journal of Philosophy 5. For Frankfurt, the question of whether V's choice to take the drug (and thereby give in to what Frankfurt classifies as a first-order desire, an immediate, unreflective wanting) is "free" or not, turns on whether it comports with the victim's second-order desires (the victim's reflected desire either to want to lead the life of a drug taker, or alternatively to stop taking drugs). It is only when a drug addict whose second-order desire is to kick the habit nevertheless reaches for the drug, that Frankfurt would classify his choice as unfree.

24 Pagett (1983) 76 Cr.App.R. 279.

25 Williams ("Finis", 409) thinks it suffices that "the police acted under pressure caused by the defendant and so were not exercising the unfettered volition presupposed by the novus actus rule" but that argument overlooks the fact that what the subsequent actor does will, in novus actus cases, necessarily be prompted to some extent by what the first actor did. The question is precisely whether, despite that connection, we evaluate the link as broken. See Hart and Honoré, Causation, 2nd ed., 136.

26 See e.g. the facts of Cheshire [1991] 1 W.L.R. 844. 
as a potentially criminally negligent cause of harm. ${ }^{27}$ Stuckenberg cuts to the chase when he drily remarks that

[a]ll versions of novus actus interveniens suffer from inconsistencies, for example in the case of ... persons acting in self-defense (e.g. shooting back at robbers and killing a bystander) where the interventions, albeit free, deliberate, and informed, are considered irrelevant. Obviously, additional aspects like foreseeability are involved. Also, the concept of "voluntariness" is equivocal and easily stretched too far, for instance if moral obligations are said to render acts of assistance or rescue "involuntary". 28

This is not to say that the substantive outcomes of the cases already mentioned are wrong. But it is difficult to see how they can be arrived at through the application of the "free, deliberate and informed intervention" formula. Two recent cases illustrate these difficulties.

In Wallace, ${ }^{29} \mathrm{D}$ performed a debilitating premeditated attack on a former lover, V. She poured acid over V's face and naked body while V was sleeping in his bed. D's aim was to disfigure V so badly that no one else would want to be with him. The attack caused horrific burns to V's face and body, with wounds so deep that they couldn't heal properly. For six months D was kept in a medically induced coma, from which he was awoken to an existence of constant pain, worsening disability and permanent extreme disfigurement. Dependent on full-time nursing care, he asked to be transferred to a medical facility in Belgium, his home country, where he then requested euthanasia - a procedure that can, under Belgian law, be lawfully carried out as a medical procedure if certain conditions are met. Following medical assessments which confirmed that he met these conditions - he was of sound mind, his request was voluntarily made, well-considered and durable, and he was in a medically futile condition of constant and unbearable physical or mental suffering that could not be alleviated -, his request was granted and the doctors treating him administered a lethal injection. Subsequently, D was charged with V's murder.

D's defence argued that the Belgian doctors' approval of the euthanasia request and their carrying it out constituted a novus actus interveniens. They stressed that euthanasia is unlawful in the UK, which they saw as an additional reason why it should be treated as a novus actus. They also suggested that the victim's request for euthanasia, given that only a patient with a sound mind who had made a considered decision could validly make such a request, broke the chain of causation.

27 The apparent inconsistency involved in holding the earlier and the independent later agent criminally responsible for the same outcome did not escape Williams ("Finis", 412), who based his criticism of the Australian decision in Russell [1933] V.L.R. 59 on this.

28 C.-F. Stuckenberg, "Causation" in M.D. Dubber and T. Hörnle (eds.), The Oxford Handbook of Criminal Law (Oxford 2014), ch. 21, 486 (references omitted). A. Brudner, "Owning Outcomes: On Intervening Causes, Thin Skulls, and Fault-undifferentiated Crimes" (1998) 11 Canadian Journal of Law and Jurisprudence 89,94 , similarly remarks that "the criterion of free, deliberate and informed activity embraces cases common sense would exclude from the category of a novus actus", forcing Hart and Honoré to "stretch the notion of involuntary conduct".

29 Wallace [2018] EWCA Crim 690, [2018] 2 Cr.App.R. 22. 
The trial judge was swayed by these arguments and ruled that there was no case to answer on the murder charge. On a successful prosecution appeal against this ruling, the Court of Appeal held that the murder charge should be left to the jury. The Court of Appeal resolved to look at this case as a suicide case and told the trial judge that the question to be put to the jury was: "Are you sure that at the time of the acid attack it was reasonably foreseeable that $[\mathrm{V}]$ would commit suicide as a result of his injuries?" 30 clearly expecting that, on this analysis, the jury would be inclined to find causation. The jury, however, did not do so. The defendant was merely convicted of causing grievous bodily harm with intent, for which - mindful of the victim's prolonged and extreme suffering before he escaped into death the trial judge imposed a life sentence with a 12-year minimum term. ${ }^{31}$

The Court of Appeal was clearly right to treat this as a victim-suicide case. While it is true that the victim died by lethal injection and not by an act he directly performed himself, it is clear that the Belgian doctors would not have given him this injection, had he not requested it. Therefore, the victim controlled the process. That the doctors also made an assessment of the victim's condition that allowed them to conclude that they were permitted by law to act on this request doesn't change the fact that their act implements the victim's wishes.

If Wallace is placed in the victim-suicide category, it is consistent with the Court of Appeal's approach in other victim-reaction cases, such as Blaue and Roberts, to ask only whether the victim's reaction was foreseeable (or so "daft" as to break the causal chain). ${ }^{32}$ But that is also a question that doesn't tell the jury anything about how they should approach this issue on the unusual facts of this case. What makes this case different from other victim-reaction cases is that the reaction is not a spontaneous one in the immediate situation created by the defendant. Contrast Wallace with a case decided in California in 1899, Lewis. ${ }^{33}$ In Lewis, the defendant had shot the victim with a shotgun multiple times. The victim, in agony, slit his own throat to speed up what the victim saw as his inevitable death, and the defendant was held to have caused that death. The authors of a leading textbook suggest that " $D$ would not have been guilty of murder if the wound had merely been painful rather than life-threatening and, knowing this, $\mathrm{V}$ had taken his life only in order to escape pain". ${ }^{34}$ This, however, is open to doubt. It seems from other victim-reaction cases that the defendant can be held responsible on a much wider principle.

\footnotetext{
${ }^{30}$ Ibid., at [86].

${ }^{31}$ The sentencing remarks of the trial judge can be found at: https://www.judiciary.uk/wp-content/uploads/ 2018/05/r-v-wallace-sentencing-1.pdf (last accessed 13 May 2021).

32 See text at notes $20-22$ above.

33 People v Lewis (1899) 124 Cal. 551, 57 Pac. 470.

34 A.P. Simester et al., Simester and Sullivan's Criminal Law: Theory and Doctrine, 7th ed. (Oxford 2019), 113.
} 
That principle says that any immediate reaction by the victim to the situation in which the defendant placed her can be causally attributed to the defendant. ${ }^{35}$ If, in Wallace, the victim had jumped out of a window immediately to put an end to his pain, that would certainly still have been laid at the door of the defendant.

But what if the reaction is not immediate, if - as in this case - it occurs some considerable time after the attack? On Hart and Honoré's formula, V's choice to seek euthanasia might initially seem like a novus actus interveniens because the competency assessment and the waiting period between request and implementation make this choice seem both deliberate and informed, and if all that "free" means is that no one forced V to ask for euthanasia, then his choice would also be considered free. ${ }^{36}$ Even more so, the Belgian doctors' conduct in acceding to the request might appear to qualify. ${ }^{37}$ Like the British customs officer in Latif ${ }^{38}$ who carried the drugs into this jurisdiction, the Belgian doctors were not prompted by Wallace to euthanise V, or acted in any way she influenced. The only matters to which they had regard were the legal framework governing the provision of healthcare in Belgium and what this meant for a patient in V's condition. If we want to overcome these possible conclusions on the facts of Wallace, we need to reconsider the Williams-Hart-Honore approach to the novus actus principle.

Before we turn to this task, let us first look at another recent case where the FDI formula spelled trouble for the prosecution, albeit that the jury did eventually find causation to be made out. This is the case of Field, ${ }^{39}$ where $\mathrm{D}$ - after convincing $\mathrm{V}$ of his affection, and knowing that $\mathrm{V}$ had made him a

35 Apart from Roberts and Blaue, discussed above, we can also point to Beech (1912) 7 Cr.App.R. 197 (victim jumps out of the window while D is kicking and hammering at the locked door) and the US case of Stephenson v State (1932) 205 Ind. 141, 179 N.E. 633 (V swallows poisonous tablets immediately after $\mathrm{D}$ has brutally raped and bitten her).

36 That this conclusion is consistent with Hart and Honoré's understanding of the novus actus principle is suggested by their criticisms of the court's finding of causation in Stephenson $v$ State where they submit that "the provision, by an unlawful act, of a reason for [V] voluntarily to kill himself ... does not amount to 'causing' the death, ... nor to 'causing' [V] to take his own life, because no compulsion is used" (Hart and Honoré, Causation, 2nd ed., 329).

37 This conclusion is explicitly drawn by F. Stark, "Driving Home Causation" [2020] Archbold Review 6 , 8. Simester and Sullivan likewise contend that "when applying the FDI principle in the context of euthanasia, attention should turn to T [the doctor] rather than [V]" but are more equivocal about what conclusion should be drawn - all they maintain is that "[n]o adequate direction on causation in Wallace should ignore [this] issue" (A.P. Simester and G.R. Sullivan, "Causing Euthanasia" (2019) 135 L.Q.R. 21, 23, 24).

38 Latif [1996] 1 W.L.R. 104 (H.L.) concerned the question how it affects the offence for which an overseas drug supplier is liable that he supplied drugs destined for Britain, not to a fellow criminal but to an undercover agent who handed them over to a customs officer who, on the instructions of his superior, brought the drugs into this jurisdiction. The House of Lords held that the customs officer could not reasonably be said to have acted on the instructions of the drug-supplier; his conduct in transporting the drugs to Britain to facilitate the trial of the supplier was therefore a break in the causal chain such that the supplier could not be said to have imported the drugs. The supplier, however, remained liable for the offence with which he had been charged because it was wide enough to cover his conduct leading up to the transport.

39 Field [2021] EWCA Crim 380. 
beneficiary of his will - had initially engaged in a sustained campaign to get $\mathrm{V}$ to believe that he was losing his mind, in the expectation that this would drive $\mathrm{V}$ to commit suicide. This had involved the secret administration of various prescription drugs to $\mathrm{V}$ over months with a view to causing episodes of confusion and disorientation. While this had indeed made V insecure and apparently very ill, $\mathrm{D}$ came to realise that $\mathrm{V}$ would not commit suicide. D therefore resolved that $\mathrm{V}$ should drink himself to death, and in furtherance of this endeavour - one evening while visiting $\mathrm{V}$ encouraged him to drink copious quantities of whisky in his company. V's death was caused by the effects of the alcohol in combination with a sedative he had also taken. The appeal turned on the question whether, on the facts alleged, V's drinking of the whisky constituted a novus actus interveniens. The trial judge had (in the relevant part) instructed the jury:

If it is proved that, with intent to kill, [D], in person, gave [V] drink then, even if [V] agreed to drink it, it would be open to you to conclude that the giving was a cause of death, unless [V]'s decision was informed in that he knew that the drink being offered to him was intended to cause his death. ${ }^{40}$

This is a surprising direction. V, after all, fully appreciated the type and strength of beverage he was ingesting. How could it matter for the "informed" nature of his decision to accept the drink offered to him that $\mathrm{D}$ intended for the drink to cause his death? This did not make the drink as such any different from what $\mathrm{V}$ thought it was. Yet the Court of Appeal upheld the conviction. In so doing, it accepted an analogy between this case and that of a weak swimmer who is encouraged by a false friend to swim out into the sea on the strength of a promise the false friend has no intention of keeping that he will come to the swimmer's aid, should he get into difficulty. In the swimmer's case, “the accused's real intention would have changed the nature of the undertaking on which the victim embarked, by rendering it more dangerous". 41

That is undoubtedly so. But, of course, the differences between the two scenarios are obvious. Whereas a weak swimmer may indeed only take heart and swim out because he falsely believes that a potential helper is on standby, there is no real parallel here to the drinker who has been lured into believing that he is drinking in the company of a friend. It is not normally the case that people drink in company because they think that this lowers the risk of possible adverse outcomes. Drinking companions are not usually perceived and valued as emergency help on hand. If $\mathrm{V}$ (as is plausible) would have declined to accept a drink from someone who he knows intends for the effects of alcohol to kill him, it is implausible that this would have been so because the offerer's intentions deprive the

\footnotetext{
${ }^{40}$ Ibid., at [52].

${ }^{41}$ Ibid., at [59]-[61].
} 
drinker of a safety net in respect of possible adverse effects of the drink. It is rather that $\mathrm{V}$ would have been put off drinking on this occasion simply because there is no pleasure involved in drinking in the company of someone who, one knows, wants one to be killed by the drink, and/or because learning of this intention would also have served as a stark reminder of the risks of overindulgence in alcohol. However, none of these considerations show that V's drinking was "not ... the result of a free, voluntary and informed decision by V" because $\mathrm{V}$ was ignorant of D's "undisclosed homicidal purpose" in serving $\mathrm{V}$ drink. ${ }^{42}$

Let us then turn to the question whether there is a more convincing way to determine when the subsequent conduct of another person "break[s] the moral connection that would otherwise have been perceived between the defendant's acts and the forbidden consequence", as Williams put it in his article. ${ }^{43}$

\section{ReBooting NovUs ACtUS}

\section{A. A Better Doctrinal Foundation for Novus Actus Interveniens?}

Findings of causal responsibility are expected to settle what, with Hart and Honoré, can be called "the question of attribution". ${ }^{44}$ An "attributive causal judgment" is one that cites the actions of a human being as the cause of some harm. ${ }^{45}$ This attribution, moreover, is made with a practical objective in mind. The attribution of causal responsibility for a harm to a person is done with a view towards holding that person legally liable for that harm. It is an evaluative judgment we make after we have explained "how it happened" and that some activity or inactivity by the defendant is part of the "how it happened" story. This evaluative judgment is no longer about explaining the occurrence of the harm. It is about deciding, in light of that explanation, whether $\mathrm{D}$ is responsible for that harm.

The idea that "a voluntary and informed decision to act in that way rather than another" 46 starts a new causal chain, absolving the previous actor from causal responsibility, has its roots in the philosophy of action. Some philosophers have taken the view that an act that is governed by B's will, and is therefore B's doing, cannot at the same time also be someone else's (say: A's) doing. Either B controls his own actions by his own will, or A controls B's actions by his (A's) will. ${ }^{47}$ Attribution of causal agency thus becomes

42 Ibid., at [60].

43 Williams, "Finis", 392.

44 Hart and Honoré, Causation, 2nd ed., 326.

45 J. Feinberg, "Causing Voluntary Actions", in his Doing and Deserving: Essays in the Theory of Responsibility (Princeton 1970), 152, 182 (reviewing and referring to Hart and Honoré, Causation, 1st ed., 22-23).

46 Kennedy (no. 2), [2007] UKHL 38, at [14].

47 This philosophical position was traced by another early reviewer of Hart and Honoré's work to a "nineteenth century version of the idea of free will, following Kant's view that man's voluntary action always 
an either-or choice between B (the second actor) and A (the first actor). When B acts voluntarily (his actions are controlled by his own will), then - notwithstanding some earlier action by A which influenced B's decision -, B is the cause of any results of his act, blocking the attribution of causal responsibility for these results to A.

This way of thinking stands behind Hart and Honoré's "free, deliberate and informed intervention" formula. The usefulness of this formula in deciding whether a subsequent agent's conduct absolves an earlier agent of causal responsibility for an outcome, was insightfully challenged by the philosopher Joel Feinberg in an early discussion of Hart and Honoré's work. ${ }^{48}$ Feinberg defends the view that there is nothing mysterious in the thought that one can cause another person's voluntary action. $\mathrm{He}$ says:

It happens commonly enough that one person, either knowingly or unintentionally, triggers the action of another .... Now the crucial question arises: if $[B]$ 's action is triggered by [A]'s, and especially if it is caused to happen by $[A]$ 's intentional triggering, how can it possibly be said without qualification to be [B]'s own action, a free, informed, deliberate, that is, "fully voluntary" act? ... When the trigger-pull is easy, and only the slightest commonplace sort of stimulus is required to set off [B's] action, then the major part of the explanation of that action will necessarily involve [B]'s own complicated self ... the more the triggering diminishes in explanatory significance, the [more willing] we are to regard [B's] act as [B's voluntary act which no longer implicates A]. ${ }^{49}$

On the flip side, if A has provided a very strong stimulus, which got B to do something that he would otherwise almost certainly have resisted or never have considered doing, then even though B still decided to do the act, B's act "belongs" to A as well; it is not exclusively B's action (even when B was not acting in concert with A).

\section{Applying Feinberg's approach to the facts of Wallace}

If we look at Wallace with Feinberg's model in mind, we cannot but see it as a perfect example of a case where "[V]'s action is triggered by [D]'s action". V's hopeless, nightmarish situation was entirely D's doing. She had put him into the state where he saw no way of continuing with his life. And what Feinberg calls the trigger-pull for making V seek his own death was anything but easy in this case. Even after he had been brought out of his coma into an existence full of pain and dependency, $\mathrm{V}$ had

\footnotetext{
starts a new chain of causation and can never be the effect of the latter". The same reviewer then went on to say that it was "hardly ever applied by German [courts and] has since been entirely abandoned as a result of vigorous criticism by practically all German writers. It is hard to explain why English and American courts persist in following it" (P.K. Ryu, "Causation in Criminal Law" 1958 (106) University of Pennsylvania Law Review 773, 782 (references omitted)).

48 Feinberg, "Causing Voluntary Actions" (emphasis added).

49 Ibid., at 169-71.
} 
clung to life in the hope that something would get better, quite prepared to endure further painful treatment if only this might help him to regain some of his mobility and a semi-independent (if still disfigured and disabled) existence. Instead, everything had only gotten worse. His physical condition had become more constraining, the wounds burned into his flesh by the acid never healed. The only person from his former life who could even bear to visit him in his suffering was his father; neither other family members nor the girlfriend for whom $\mathrm{V}$ had wanted to leave $\mathrm{D}$, could cope. Hope of gradual improvement of his condition had nevertheless sustained him. It was only when such improvement was medically ruled out that he sought to die. It is therefore unquestionable that the dominant factor in his decision to seek death were the injuries D had inflicted upon him. He was as resilient to misfortune as anyone could ever be, and only the strongest imaginable stimulus - complete ruination of his life and future prospects - could bring him to opt for death. Moreover, this was (to use Feinberg's phrase) “caused to happen by [D]'s intentional triggering": she wanted to maim him so badly that he couldn't have a happy life with anyone else. Consequently, as Feinberg put it, it cannot "possibly be said without qualification" that the decision to die is V's " fully voluntary' act". Quite the opposite: this development belongs at least as much to $\mathrm{D}$ as it does to V. On a Feinbergian analysis, Wallace is as clear a case as it gets where the chain of causation is not broken by V's decision to die. ${ }^{50}$

So what about the fact that the manner in which V's death came about was by voluntary euthanasia, provided to him by the Belgian doctors? In their comment on Wallace, Simester and Sullivan draw attention to the following aspects of the doctors' provision of euthanasia: "It was T's (the doctor's) choice to give the injection: there was no obligation to do so" (an argument that I take to allude to the possibility that the doctor in question could have avoided providing euthanasia by raising a conscientious objection); "the act of injection was a calm, considered and deliberate act", and "[m]ost likely, T chose to act for reasons of compassion". ${ }^{51}$ Should any of these factors prompt us to evaluate the provision of euthanasia as a break in the causal chain? It appears to me that they should not. The decisive point is still that, in the Belgian context, euthanasia can, if certain conditions are met, be provided as a medical service. Imagine a case where the defendant

${ }^{50}$ It is worth noting that the Feinbergian approach generates doubts that Blaue was correctly decided. After all, here V's decision to refuse treatment owes everything to idiosyncratic personal beliefs and nothing to the lack of a prospect for cure or amelioration. While I do not want to enter into a detailed analysis of Blaue here, it is worth noting that the apparent unreasonableness of V's decision to refuse life-saving treatment does trouble commentators, who tend to offer additional arguments in its support. See e.g. Klimchuk, "Thin Skulls", 134, who invokes the "protected status of religious beliefs" to insulate V's decision against a reasonableness analysis, and Hart and Honoré, Causation, 2nd ed., 361, who argue that what matters is "not whether it is reasonable ... to believe that blood transfusion is wrong" but that "a person whose life is in danger [cannot] reasonably be expected to abandon a firmly held religious belief".

51 Simester and Sullivan, "Causing Euthanasia", 24. 
rapes the victim, the victim falls pregnant, and the victim then decides to have an abortion. In many jurisdictions, doctors have a choice about whether they will carry out abortions or whether they will signal that they are personally unavailable to perform abortions on grounds of a conscientious objection. That would surely raise no doubt that D remains causally responsible for V's abortion. If we look at events here in those terms, the crucial consideration is that V's euthanasia was, where it was carried out, provided as an appropriate medical procedure. And, of course, one would want medical service providers to be as deliberate and informed as they can possibly be in providing medical treatment. It is hardly a new development in the case law that such treatment, even if it is the immediate cause of death, does not relieve D of causal responsibility for this outcome. ${ }^{52}$ The FDI formula is simply a distraction in this context.

Should it make a difference to the causal analysis whether the treatment the victim was provided with in another jurisdiction would be unlawful treatment, even amount to a criminal offence, in this jurisdiction? ${ }^{53}$ It is unclear on what basis this aspect should affect causal responsibilityattribution. It cannot turn the medical intervention that the doctors have performed into something other than it was: a procedure that was judged to be medically indicated where it was carried out. Recall the parallel drawn above with abortion: why would a jurisdiction which still prohibits this procedure want to release $\mathrm{D}$, the rapist, from causal responsibility for the fact that $\mathrm{V}$ underwent it elsewhere? Looked at in this way, it is clear that the Belgian doctors acceding to and carrying out V's request for euthanasia in Belgium, having evaluated it as meeting the conditions which make these requests valid under Belgian law, does not constitute a break in the causal chain in the Wallace case. ${ }^{54}$

\section{Applying Feinberg's approach to the facts of Field}

In Field, the main source of discomfort with the judgment arises from the apparent need to turn V's acceptance of the whisky proffered to him into an "uninformed" decision in light of the fact that V was unaware of D's secret homicidal intentions. Of course, all our instincts tell us that D's homicidal intentions must be important. What is doubtful is only how ignorance of

\footnotetext{
52 See Malcherek [1981] 1 W.L.R. 690 (C.A.).

53 This issue was raised by the defence but is not addressed in Simester and Sullivan's comment.

54 What may be more debatable is whether D should remain responsible for V's death also in a case where V's suffering compels $T$ to perform a mercy killing. What if a close family member had resolved to put $\mathrm{V}$ out of his misery? Without wanting to take a final position on this question here, it appears to me that on a Feinbergian analysis, the decision to perform a mercy killing could in appropriate cases be evaluated as one that owes little to the idiosyncratic personal psychological makeup of the mercy killer and everything to the protective instincts and emotional responses triggered by the extreme suffering of a beloved other (a child, parent, or partner), such that the suffering which $\mathrm{D}$ inflicted on $\mathrm{V}$ provides the difficult trigger-pull on T. I would therefore submit that, even where the intervention $\mathrm{T}$ performs is a crime of intent, it remains possible to assess it as an act that does not break the chain of causation.
} 
these intentions can turn V's choice to drink what he knows perfectly well is whisky into an uninformed choice. ${ }^{55}$

Feinberg does not think that the "FDI formula" gives any helpful guidance in identifying instances where the earlier agent can no longer be said to have caused an outcome most immediately brought about by a later agent. Whereas Hart and Honore "prefer the voluntary intervention principle", Feinberg states, "I opt for the principle that "the more expectable human behavior is, whether voluntary or not, the less likely it is to negative causal connection". 56 What he means by "expectable" is not clarified any further. But in light of Feinberg's own examples, we can take it that, broadly speaking, two kinds of reactions are "expectable": reactions which - our general experience of life tells us - are "just the sort of thing that someone would do", and reactions that (however irregular or highly unusual they might be) were expected by $D$ due to some special information $\mathrm{D}$ had about the behavioural inclinations of the intervener. ${ }^{57}$

Once we approach the facts of Field from this direction, our attention is drawn to the sustained campaign of manipulation to which $D$ had subjected $\mathrm{V}$ and which had already been instrumental in turning $\mathrm{V}$ into someone who didn't trust his own mind and his own future any more. It is against this backdrop of prolonged surreptitious undermining of V's self-assurance and belief in his own sanity by D that D's active encouraging of V's drinking on the night in question needs to be judged. V's drinking, as such, was much less attributable to his personal tastes and much more explicable in terms of $\mathrm{D}$ having over a period of time done what he could to turn $\mathrm{V}$ into a heavy drinker by giving him reasons to seek escape from his problems in alcohol, than an ordinary case of someone who turns to drink.

But note that Feinberg also carefully avoids turning this consideration into a "bright line" division. He formulates it as a criterion that is inherently scalar and can be present to different degrees: the more expectable the reaction, the less likely it is that it will negative the causal connection. Thus whether the connection is preserved or negatived in cases where the reaction was expectable always requires further evaluative assessment in light of the specific facts of the case. One very important aspect (the one that Feinberg picks up on when he speaks of the trigger-pull being easy or difficult) is the question to what degree a reaction is attributable to the personality of the second agent (maybe he is the depressive type such that the slightest misfortune will generate suicidal thoughts) and to what degree it is

55 A reviewer suggested that $\mathrm{V}$ was possibly unaware of the heightened dangers of combining heavy drinking with a sedative but that learning of D's intention for his drinking to cause his death on this occasion would have brought these dangers home to him. On this basis it may be arguable that V was "uninformed" about the dangers of drinking.

56 Feinberg, "Causing Voluntary Actions", 184.

57 Ibid., at 156-57, gives (inter alia) the example of suicidal Mr. Blue, who happens to know of $\mathrm{Mr}$, Firmview's firm intention to shoot anyone dead who says $\mathrm{X}$ to him, and who says $\mathrm{X}$ to Mr. Firmview in order to be shot dead by him, which Mr. Firmview obligingly does. 
explained by the extraordinary strength of the factor introduced by the earlier agent's actions (even the greatest optimist would have been worn down by this much suffering). But clearly, when the intervener's particular behavioural inclinations or weaknesses are consciously exploited by the earlier actor, the fact that the trigger-pull was (obviously) easy does not relieve the earlier actor of responsibility. ${ }^{58}$

Such nuanced and contextual assessment of the facts of Wallace and Field quickly leads to another question - whether the nature and strength of D's mental connection to the outcome that eventuated should also play a role. Whatever else V's acceptance of drinks proffered to him by $\mathrm{D}$ signified, it was part and parcel of D's comprehensive efforts to increase the likelihood that V would come to a premature end. It is this factor that suggests to us that $\mathrm{D}$ cannot point to the fact that $\mathrm{V}$ accepted the drink offered to him, just like in cases of intentional attacks such as Wallace (where the court emphasised that "[t]he intervening acts of [V] and the doctors were not ... unconnected with the fault element of [D]'s conduct"59) the courts have stressed that "it does not lie in the mouth of the assailant to say that his victim's [situational responses] were unreasonable". ${ }^{60}$

\section{B. Why D's Intention Matters for the Attribution of Causal Responsibility}

In Feinberg's view, the earlier actor's intention to produce a certain reaction by the later actor that brings about the outcome strongly factors into the assessment of whether an outcome should still be attributed to the earlier agent. When considering whether B's, the later agent's, conduct makes the outcome entirely B's own, Feinberg emphasises not just the strength of the trigger-pull which A's earlier action provided for B, but also notes that A remains causally responsible for the outcome, on the basis that B's act cannot be said to be entirely his own, fully voluntary act, "especially if it is caused to happen by [A]'s intentional triggering". ${ }^{61}$

Many decided cases stress D's intention to bring about the prohibited outcome as a factor relevant to the evaluative stage of the causation analysis - indeed, this has led to the adage that "intended consequences are never too remote". ${ }^{62}$ But why should D's intention matter for causal responsibility-attribution? To see this, we need to reflect on the function

58 Though we may want to restrict this to responsibility-attribution for directly intended outcomes, and not admit those that are foreseen as practically certain into the fold (e.g. in cases where D knows that, if she leaves her boyfriend, he will commit suicide, because he has credibly threatened to do exactly that, should she ever leave him).

59 Wallace [2018] EWCA Crim 690, at [60].

${ }^{60}$ Blaue [1975] 1 W.L.R. 1411, 1415.

${ }^{61}$ Feinberg, "Causing Voluntary Actions", 170 (emphasis added).

62 J. Gardner, "Rationality and the Rule of Law in Offences Against the Person" [1994] C.L.J. 502, 506, claims that "the familiar maxim that intended consequences are never too remote ... paints a somewhat exaggerated picture, but to the extent that it speaks the truth it proceeds from the thought that those who intend some result could otherwise ... evade a ... legal rule which is means-specific simply by adopting different means. ... So there is good reason ... to withdraw ... means-specificity from a ... rule where 
served by the attribution-limiting criterion that intention is taken by the courts to override: an outcome's foreseeability.

Foreseeability developed as a hidden fault restriction to purely objective causal responsibility-attribution. ${ }^{63}$ It first came to be accepted in cases where the intervening event was a natural one and where the project was undertaken without the consequence in D's sight but it has also been deployed by the courts when the subsequent event is a human act. The proposition that intended consequences are never too remote pulls in the other direction, possibly bringing back into the fold of D's causal responsibility outcomes that came about by a most surprising turn of events.

This extended attribution of causal responsibility for intended outcomes when the causal pathway could not reasonably be foreseen is explicitly supported by Williams, who insists that unforeseeability (whether of natural events or of subsequent human actions) should never "let ... off ill-intentioned people merely because of an unforeseeable twist in causation". ${ }^{64}$ The real question is why intention should make a difference. One argument one could make relies on fairness. Foreseeability developed as a criterion that restricts causal responsibility-attribution to protect an agent who causes a prohibited outcome through "sheer bad luck". From this perspective, the "super-fault state" of intention suggests that this agent hardly deserves protection from having the success of his project (the materialisation of his intentions) attributed to him, however unlikely and unforeseeable success in the first place, or the precise pathway to his success, may have been. This seems to be the consideration that carries Williams's discussion of Michael ${ }^{65}$ and of the harlot's case ${ }^{66}$ (although it appears that Williams himself has not been entirely consistent on this point: in the second edition of his famous treatise on the general part of criminal law, he asserted that "if D gives [V] a poisoned pill, intending to murder him, and [V] unwittingly takes the pill but it gets stuck in his windpipe and he dies of suffocation, D would not be convicted of murder" 67 - to which one reviewer, referring to the case of McIntyre ${ }^{68}$ immediately retorted: "Yet it has been held that if D kicks [V] with intent to kill,

its violation consists in the intentional pursuit or achievement of some result". Gardner himself (ibid., at 506 , note 12) believes that this provides no reason to "withdraw the protection of novus actus interveniens which, being a doctrine concerning the effects on liability of the unexpected, cannot ... be manipulated", but this qualification misses (as I will argue in the text) the significance of the agent taking his conduct to be capable of achieving its intended end.

63 For an interesting early discussion, see Ryu, "Causation in Criminal Law", 789ff.

64 Williams, "Finis", 402.

65 In Michael (1894) 173 E.R. 867, a mother, intending for her child to die, gave a bottle with poison to the child's nurse, stating it was medicine and instructing her to feed it to the child. The nurse did not do so but another child of the household fed the contents of the bottle to the baby. The mother was convicted of murder.

66 In the harlot's case, a woman placed her newborn in an orchard to let it die from exposure, but the newborn was killed by a bird of prey.

67 G. Williams, Criminal Law: The General Part, 2nd ed. (London 1961), 125.

68 McIntyre (1847) 2 Cox 379. 
and a doctor gives [V] brandy which goes the wrong way into [V]'s lungs and chokes him to death D is guilty of murder." 69 )

A philosopher may, however, press us for an explanation of why it remains fair to attribute responsibility to the initiator of a freaky causal chain when the outcome was intended. We can give the philosopher a satisfying answer when we attend more closely to the function of the foreseeability requirement in the causation analysis, namely that it "is consistent with the idea of a result bearing the mark of wrongdoing. [It] recognizes that foreseeable results are part of the reasons for not engaging in the conduct". ${ }^{70}$ Staying with the idea that D needs to have "reasons for not engaging in the conduct", we can now put the difference between unintended and intended outcomes in this way: When the possibility of conduct $\mathrm{C}$ leading to consequence $\mathrm{Y}$ is not one that $\mathrm{D}$ can be expected to perceive, then that gives $\mathrm{D}$ no reason not to perform the conduct, and so it would be unfair to hold him responsible for the bad consequence of it. ${ }^{71}$ But where D intends to bring about the very consequence that did occur (albeit that it was highly improbable, or came about only via a freaky causal sequence), he already has every reason he needs not to engage in the conduct: he shouldn't try to bring about this prohibited consequence. ${ }^{72}$ This is why when $\mathrm{D}$ intended for his conduct to produce the consequence, it is quite fair to hold him responsible for this consequence even when it occurred on a surprising path.

It is worth pausing here for a moment because this is a point whose fundamental importance is easily overlooked. It shows us that we have good reason to look differently upon intended outcomes and unintended outcomes, treating the former as the product of D's earlier act even when D had unusually little control over the causal sequence and/or that sequence unfolded along entirely unpredictable lines. What justifies causal responsibility-attribution in such cases is the consideration that $\mathrm{D}$, after all, did what he did because he thought it could (perhaps with a lot of luck) produce the result he aspired to produce, and that not only means that he shouldn't have done what he did but also that in an important sense he made his own luck by doing what he did and succeeding against the odds (and maybe even to his own surprise). The arguments given in the literature against an extended responsibility-attribution for intended

${ }^{69}$ R.N. Gooderson, "Book Reviews: Criminal Law: The General Part. Second edition. By Glanville Williams" [1963] C.L.J. 141, 142.

70 D. Galloway, "Causation in Criminal Law: Interventions, Thin Skulls and Lost Chances" (1989) 14 Queens' Law Journal 71, 76.

71 This is Galloway's argument. See also S. Yeo, "Blamable Causation" (2000) 24 Crim.L.J. 144, 152 Note, however, that we may need to qualify this statement. It is not necessarily the case that all foreseeable results are part of the reason for not engaging in the conduct. We may have to argue, more narrowly, that only results that the prohibition of the conduct aims to avoid are part of the reason for not engaging in the conduct.

72 This point is missed by Galloway, "Causation". 
outcomes thus largely miss the mark. Writers there are troubled by such apparent counter-examples as " $\mathrm{D}$, who hopes to inherit under his uncle's will, suggests that his uncle take a holiday cruise, hoping that the ship will sink, and it does"73 - but these are no counter-examples because one cannot realistically see D's recommendation of a holiday in this case as part of a project $D$ engages in to bring about the uncle's death - very much in contrast to, say, the sustained campaign of driving $\mathrm{V}$ into depression and drink that D engaged in in Field.

It is important to note that this justification for an extended attribution principle for intended outcomes only applies when bringing about the outcome is criminal under some offence, as this supplies D with the reason he needs not to try to bring it about. It is also worth noting that the consideration that the prohibited outcome was intended by $\mathrm{D}$ is, again, not absolute but (like everything at the evaluative stage of the causation analysis) scalar. We may therefore sometimes be persuaded that the intended outcome really did now occur through a sequence of such exquisite improbability that can no longer be laid at D's door.

\section{Beyond the Novus Actus Principle: Discounting Active Causes in Concurrent Causation}

In most cases where issues of causal responsibility are decided in D's favour, so that D is not held causally responsible despite the fact that he created one of the factual preconditions for the outcome to occur, the "severing consideration" relates to a subsequent event that, in the historical timeline, occurs between the moment when D makes his causal contribution and the occurrence of the prohibited result. But we can also be troubled by the question whether it is appropriate to hold an agent causally responsible for a harmful outcome when there is only one stage to the harmful incident and the defendant is unquestionably setting a direct, "but for" cause of the harm that occurs. This is the issue raised by the Supreme Court's judgment in Hughes,${ }^{74}$ where the court (allowing D's appeal and overruling another Court of Appeal decision involving a different defendant ${ }^{75}$ ) held that D had not caused V's death when D, an unlicensed driver driving an uninsured vehicle, had collided with an oncoming car that had suddenly swerved onto D's side of the road. The driver of that car, who was killed in the accident, had been overtired and high on heroin. D, by contrast, had been driving carefully and within the speed limit. The question for the court was whether D was liable for an offence of "causing

\footnotetext{
${ }^{73}$ For discussion, see A. Walen and B. Weisser, "Causation and Responsibility for Outcomes" in K. Ambos et al. (eds.), Core Concepts in Criminal Law and Criminal Justice, vol. II (Cambridge, forthcoming), ch. 3, Part III.

74 Hughes [2013] UKSC 56, [2013] 1 W.L.R. 2461.

75 Williams (Jason John) [2010] EWCA Crim 2552, [2011] 1 W.L.R. 588.
} 
death by driving while unlicensed, disqualified or uninsured" contrary to section 3ZB of the Road Traffic Act $1988 .{ }^{76}$ On the face of it, this offence merely requires that $\mathrm{D}$ is driving a motor vehicle when he shouldn't be driving it because of his lack of a license and/or insurance, and that V's death is caused by reason of D's driving of the car. Applying ordinary causal principles, the Court of Appeal had therefore concluded that D's driving of the car was a but-for and more than de minimis cause of the fatal accident, in that the accident would not have occurred had D not been driving the car. ${ }^{77}$ The Court of Appeal had, moreover, reasoned that it was clear that Parliament had not wanted to include an element of fault in relation to the manner of D's driving into this offence; instead, it had intended to make D strictly liable for the consequences of taking a vehicle on the road when he was disqualified or the vehicle was uninsured. The Supreme Court, by contrast, concluded that ordinary causal principles require a different conclusion, observing that

there is no logical or satisfactory intermediate position between holding (a) that the law imposes guilt of homicide whenever the unlicensed motorist is involved in a fatal accident and (b) that he is guilty of causing death only when there is some additional feature of his driving which is causative in a common sense view and the latter entails there being something in the manner of his driving which is open to proper criticism. ${ }^{78}$

The attempts to make sense of Hughes are by now legion, and constraints of space prevent me from engaging with them fully here. Most defenders of the judgment share the view that it is a certain quality of the driving that must be required, but disagree over what quality it is, and why. Ormerod and Child suggest that the Supreme Court simply "re-endorse[s] a requirement for blameworthiness". ${ }^{79}$ That view is supported by the court's own use of the term "fault" when it explains that "section 3ZB requires at least some act or omission in the control of the car, which involves some element of fault, whether amounting to careless/inconsiderate driving or not". 80 The downside of this interpretation is that it leaves the Court of Appeal's point that Parliament quite clearly did not want to create a faultsensitive offence unaddressed. Dsouza's analysis turns on a broader contention that, when it comes to active conduct, we must distinguish between

76 In 2015 Parliament created two new offences of "causing death by driving while disqualified" (previously an offence under section $3 Z \mathrm{ZB}$ ), and of "causing serious injury by driving while disqualified", the explanatory notes stressing, with reference to Hughes, that "for a person to be convicted of these offences there must be something open to proper criticism in the way in which he or she was driving which contributed more than minimally to the death or serious injury". See Criminal Justice and Courts Act 2015, explanatory notes to new sections 3ZC and 3ZD of the Road Traffic Act 1988.

$77 M H$ [2011] EWCA Crim 1508, [2011] 4 All E.R. 761.

78 Hughes [2013] UKSC 56, at [32].

79 J. Child and D. Ormerod, Smith and Hogan's Essentials of Criminal Law, 3rd ed. (Oxford 2015), 64. The point is in substance maintained by the authors in the most recent edition.

${ }^{80}$ Hughes [2013] UKSC 56, at [36]. 
simple doings and commissions (akin to the distinction we make between simple non-doings and omissions). ${ }^{81}$ As regards section $3 \mathrm{ZB}$, he then develops an interpretation of "causing death by driving without insurance/a license" which contrasts the "by driving" element with the pure conduct crimes of driving without a license/insurance. On this difference he hangs a broader argument that "by driving" signifies that something about the driving has to qualify it for offence-commission - and that something, in his view, consists in "faulty driving" being done by an individual qualified to commit the offence (that qualification pertaining to the driver's absence of a license or lack of insurance) ${ }^{82}$ This is a possible approach. It, however, entirely de-emphasises the causation issue, ${ }^{83}$ and the question that I want to pursue here is what the Hughes judgment tells us about how to conduct our causal enquiries.

As Stuckenberg observes, "[c]ourts in many jurisdictions have long required that the casual connection must be shown to exist between that aspect of a defendant's conduct which is illegal (wrongful, tortious) and the prohibited result". ${ }^{84}$ It is, however, only on charges of negligent manslaughter that the criminal courts in England and Wales have clearly accepted this familiar principle. ${ }^{85}$ Moreover, even if the principle was followed in the present case, it is unclear what the wrongful aspect of D's conduct is. If it is the fact that $\mathrm{D}$ does not have a license or insurance for his vehicle, it would be logically impossible for the wrongful aspect of his conduct ever to connect to the resultant harm. ${ }^{86}$ If, by contrast, the wrongful aspect is that $\mathrm{D}$ drives a vehicle when he is not allowed to do so, focusing on the wrongful aspect will provide no limitation. Focusing on the wrongful

81 M. Dsouza, "Beyond Acts and Omissions: Remark-able Criminal Conduct" (2021) Legal Studies 1, 7-11. The point has been extensively debated in the German literature, including its implications for the division of labour between offence-qualifying behaviour analysis and principles governing the ascription of outcome responsibility to agents (what in the Anglo-American context is referred to as legal causation). See esp. W. Frisch, Tatbestandsmäßiges Verhalten und Zurechnung des Erfolgs (Heidelberg 1988).

82 Dsouza, "Remark-able Criminal Conduct", 12-13.

83 Dsouza remains equivocal about the causal question, merely stating that "if we read Hughes as building culpability into the rules of causation, we could (at significant, probably prohibitive, cost to the coherence of the rules of causation) narrow the scope of broad conduct offences where the rules of causation are relevant" ("Remark-able Criminal Conduct", 15 (references omitted)).

84 Stuckenberg, "Causation", 476 (references omitted).

85 Dalloway (1847) 2 Cox C.C. 273: D drove a horse cart without holding on to the reins. A child jumped out right in front of the cart, was caught in the wheels, and died. D was charged with negligent manslaughter. The court held that in order to establish whether D had caused V's death by his negligence, the relevant question was whether D's failure to hold on to the reins while driving the cart had caused V's death.

86 The absence of a license or insurance as such will not form a necessary element in an explanation of why the accident happened. Compare Stuckenberg's discussion ("Causation", 476) of an example given by Williams ("Causation in the Law", 64ff.) which differentiates between the hypotheticals of a wife who, mistaking it for medicine, swallows a poisonous cleaning tablet from a package D has failed to label appropriately, and a three-year-old child who does the same - the fact that the package was unlabelled (the wrongful aspect of D's conduct) is only relevant to a description of the causal pathway of the harm that befell the wife, but not the child, since the child couldn't read anyway. 
aspect of D's conduct thus provides us with little help in the Hughes case, as it either proves too much or too little.

A third possibility is to focus more narrowly on what interpersonal wrong the prohibition may be trying to prevent, as Turton and Kyd have done. ${ }^{87}$ This leads them to distinguish the wrong of driving an uninsured vehicle (the requirement of insurance aims to assure $\mathrm{V}$ of compensation in the case of an accident for which D is to some extent liable) from the wrong of driving when disqualified or unlicensed (the interpersonal wrong to be prevented here is accidents due to decreased road safety). That split itself is problematic because it leaves one variant of the offence (causing death by driving without insurance) without any field of possible application. But the position also seems to arrive at too harsh a result for the unlicensed or disqualified driver. If we are to assume that the driving activity of any unlicensed or disqualified driver as such constitutes an "increased risk of harm on the roads", then this analysis leads us straight back into attributing causal responsibility to any such driver involved in an accident, even though he may not have driven in a flawed manner at that exact moment. If a narrower description of the relevant wrong is to be preferred, it is unclear (at least to me) how we would arrive at it.

There is nevertheless some value in this approach, because it invites us to reflect on the purpose of the legislation. Parliament's objective in prohibiting people to drive unless they are licensed and their vehicle is insured is to promote road safety. The requirement of a valid license exists to ensure that drivers know the rules of the road, can handle the mechanical side of driving their vehicles competently and generally make a successful effort of complying with the rules of the road. The aim is to ensure that the presence of this particular driver on the road only creates an acceptable level of risk to other road users. The requirement of valid insurance is also, ultimately, connected to making sure that other road users are only exposed to an acceptable level of risk. Insurance provides some reassurance of the roadworthiness of cars (otherwise they would not be insurable) and some assurance that damages can be paid for.

Behind the legislation stands a general assumption about the quality of driving to be expected from unlicensed or uninsured drivers. In general terms, these drivers pose greater risks to others on the road than licensed and insured drivers do. But that doesn't mean - and here's the flaw in the drafting of section 3ZB- that whenever an unlicensed or uninsured driver is involved in an accident, the fact that this driver was possibly a less competent driver than other drivers or that his vehicle lacked insurance, played any role at all in how the accident happened. The facts of Hughes

\footnotetext{
${ }^{87}$ G. Turton and S. Kyd, "Causing Controversy: Interpreting the Requirements of Causation in Criminal Law and Tort Law" (2019) 70 Northern Ireland Legal Quarterly 425.
} 
provide a clear example of a case where any increased accident risk that may have been connected to D's lack of a license or the state of his vehicle, played no role at all.

The best explanation for the judgment in Hughes is that the court wants to make sure that it is only when the general risks that the prohibition abstractly wants to guard against - the risks that $\mathrm{D}$ is a less competent driver than the average licensed driver and that his vehicle might not be fully roadworthy - were concretely at play in the situation. That is why the Supreme Court requires that something must have been the matter with D's driving (or, I would add, with the state of his vehicle) that played a role in the accident. The best explanation for the Supreme Court's judgment is that it differentiates between abstract and concrete risks with respect to the dangers that the prohibition seeks to control. Parliament was concerned that unlicensed, disqualified or uninsured drivers were, as a class, less competent and therefore more risky presences on the road than licensed and insured drivers. Causal responsibility requires a morally salient connection between the event which occurred and the risks the state tries to control through the prohibition. This connection does not obtain when there was nothing in the manner of D's driving that contributed to the accident.

By insisting that $\mathrm{D}$ is guilty of causing death only when there was "something in the manner of his driving which is open to proper criticism", the Supreme Court formulates a test for when the reason why the state only wants to see licensed drivers and insured vehicles on the road (making sure that only people who can drive safely and vehicles which can be driven safely enter traffic) is in play when considering D's role in the accident.

The Supreme Court's test certainly takes us in the right direction for establishing a morally salient connection between the risks the prohibition tries to control, and the resulting harm. One might only consider whether the judgment goes far enough. Problematically, the court suggests that an unlicensed, disqualified or uninsured driver might be held liable for "causing death" if he was "driving slightly in excess of the speed limit ... safely and well at $34 \mathrm{mph}$ in a $30 \mathrm{mph}$ limit ... [and] was unable to stop before striking the oncoming drunken driver's car, but would have been able to stop if travelling within the speed limit". ${ }^{88}$ But it must be doubted whether this is a case where the reason why D should not be out on the road (making sure that only people who can drive safely and vehicles which can be driven safely enter traffic) is really in play. Driving slightly in excess of speed limits where this can be done safely is absolutely commonplace behaviour among drivers. The risk D created in these hypothetical circumstances would be no higher than the risk that a properly licensed and insured driver would also pose. If this is so, then responsibility for V's death should not be

${ }^{88}$ Hughes [2013] UKSC 56, at [32]. 
attributed to D just because D was unlicensed, disqualified, or his vehicle uninsured.

Interpreted in this way, the judgment in Hughes represents a significant legal development that brings the English position closer to the Continental one, where it has long been recognised that a consequence can only be imputed to the defendant if it resulted from risks the defendant created which the prohibition was meant to guard against. ${ }^{89}$ Reading Hughes as endorsing a broader principle of causation also offers the best explanation for why the Supreme Court in a subsequent case insisted on the same minimal fault requirement in respect of another offence, that of aggravated vehicle taking. ${ }^{90}$ To my mind, this suggests that there is a broader principle of causation at work here - a principle that makes sure that causal responsibility is only attributed to defendants when their conduct concretely gave rise to the kinds of risks that the prohibition they have breached is abstractly trying to prevent.

\section{How DifFERENT ARE OMISSIONS?}

In "Finis for Novus Actus", Williams's most trenchant criticism was reserved for the Draft Code's provision on causation by omission, which provided that "[a] person causes a result when ... he omits to do an act which might prevent its occurrence and which he is under a duty to do according to the law relating to the offence". ${ }^{91}$ Pointing out that this would mean that "the omitter can be convicted even though [quasi-]factual $^{92}$ causation has not been proved to the standard required for proof in a criminal case", Williams considered the proposal "preposterous". $93 \mathrm{He}$ particularly objected to the differing outcomes such a provision would produce for a parent who "fail[s] to provide medical attention for their sick child, who dies, [and who] can be convicted ... if the medical evidence indicates any reasonable possibility that the child could have been saved" compared to a parent who violently "assaults his child, and causes the child to fall and sustain an injury, later dying in hospital" and against whom "the prosecution [must] prove the causal connection beyond reasonable doubt". 94

${ }^{89}$ On the Continental imputation doctrine, see Stuckenberg, "Causation".

${ }^{90}$ In Taylor [2016] UKSC 5, [2016] 1 W.L.R. 500, D had stolen a car and later been involved in an accident with the stolen vehicle.

${ }^{91}$ Law Commission, A Criminal Code for England and Wales (London 1989), LAW COM No. 177, clause $17(1)$

92 Williams uses the word "factual" here, but many writers would take issue with this word in this context, since the relation is not one of physical-mechanical causation but is established by asking the hypothetical question whether, had the omitter done what the duty required him to do, this would have averted the harmful outcome. Whatever the linguistic preference, the criminal courts require that the fact-finder give an affirmative answer to this question. I will use the phrase "quasi-factual causation".

93 Williams, "Finis", 414.

94 Ibid., at 414. 
Williams thought that the point was not likely to be of great practical importance (mainly because in the case of the negligent parent, fall-back offences of child neglect were available). But recently the question what (in fact and in law) can ground a finding of causation by omission became a live issue. In Broughton, ${ }^{95} \mathrm{D}$ and his girlfriend, V, attended an open-air festival. At V's request D had brought pills containing ecstasy and ketamine (a party drug) along. Sometime in the afternoon $\mathrm{D}$ and $\mathrm{V}$ walked across to a small woodland just outside the festival grounds and $\mathrm{V}$ took one of the pills. It quickly became apparent to $D$ that she was having a bad trip. She walked into a thicket full of brambles, slapped herself and talked incomprehensibly with increasing agitation. D became very concerned and tried to contact various people on his cellphone, but reception was bad and the people D spoke to misunderstood D's information about their location. Hours later D eventually walked across to the main festival area and alerted two guards. But when he tried to lead them to $\mathrm{V}$ he couldn't find the spot again. V's dead body was discovered some hours later.

The evidence on causation had been as follows: It was clear that the victim had died from a bad reaction to the pill which the defendant had brought to the festival for her at her request. But bad reactions from this particular cocktail of drugs are rare and doctors do not have much experience with it. Hence the expert said that the most he could say was that there was a very good chance, in the region of 90 per cent, that $\mathrm{V}$ would have survived if $\mathrm{D}$ had brought her to the medical tent at the earliest time when he realised that she was seriously unwell (which was about three hours before he did walk across to the main grounds to get the guards' attention). But the expert also conceded that it was possible that medical attention might not have saved $\mathrm{V}$.

The Court of Appeal overturned D's conviction for manslaughter. It said:

There were two concurrent causes of death in issue: firstly, the effect of the drugs taken by [the victim] and secondly want of medical attention after the time when her condition became obviously critical. There was no evidence ... of a non-expert nature which could help answer the relevant question.

It is unhelpful to attempt to contrast scientific certainty (put at 100 per cent) with a different figure of legal certainty. Human beings asked the question whether they are sure of something do not think in those terms. In the context of causation in this very sad case the task of the jury was to ask whether the evidence established to the criminal standard that, with [timely] medical intervention, [V] would have lived. In short, had the prosecution excluded the realistic possibility that, despite such treatment, [V] would have died?

In our judgement none of [the medical expert's] descriptive language achieved that. Even his description of a 90 per cent chance of survival [at

95 Broughton [2020] EWCA Crim 1093, [2021] 1 W.L.R. 543. 
the relevant time], were medical help available, leaves a realistic possibility that she would [not] have lived. ${ }^{96}$

The jury had, of course, not been deterred by such logic from feeling sure that the victim would have been saved if the defendant had brought her to the medical tent three hours earlier. But the Court of Appeal thinks that the jury simply didn't have enough evidence before it to be sure of that: "[T]his is one of the rare cases ... where the expert evidence was all that the jury had to assist them in answering the question of causation. That expert evidence was not capable of establishing causation to the criminal standard". 97

Consequently, the trial judge should have withdrawn the question of causation from the jury. There wasn't evidence on which they could legitimately be sure that the defendant's failure to seek help in an effective manner when he should have done so had shortened the victim's life because they couldn't be sure that, if he had sought such help, it would have saved the victim from dying.

The issues raised by this case have also troubled the criminal courts in other jurisdictions. In a German case decided in 1987, a callous husband failed to call an ambulance for his injured wife. The Federal Supreme Court (BGH) decided that this failure could only be said to have caused the wife's death if it could be established with practical certainty that immediate surgery would have saved her life. Since this could not be shown, the husband was acquitted of homicide by omission. ${ }^{98}$ In another case, a doctor who had failed to arrange radiation therapy for a cancer patient was held not to have committed negligent manslaughter under German law due to the absence of a causal link to the patient's death when all that could be said was that, statistically speaking, 90 per cent of patients suffering from this type of cancer who receive this treatment survive on average for 5-10 years longer than patients who do not receive the treatment. ${ }^{99}$ It has been suggested that, even within the bounds of standard analyses of quasi-factual causation, the courts could have arrived at a different conclusion in these cases by posing the causal question narrowly about whether $\mathrm{V}$ would have suffered precisely the same harm in precisely the same place at precisely the same time. ${ }^{100}$ Had the callous husband called an ambulance, then, even if his wife had failed to survive, she would have died in hospital

96 Ibid., at [99]-[101]. It is important to note that D could not be held causally responsible simply on the basis that he had provided the drug to $\mathrm{V}$ since V, like the victim in Kennedy (no 2), had clearly chosen to take the drug. However, assuming (and accepting) that, as her boyfriend and drug-provider he owed her a duty of care in these circumstances, he could be causally responsible for her death based on his omission to seek help for her (similar to what had been held in a case where D had provided drugs to her half-sister and later refrained from seeking help: Evans [2009] EWCA Crim 650, [2009] 2 Cr. App. R. 10).

97 Broughton [2020] EWCA Crim 1093, at [103] Broughton was followed in $R v$ WTL Ltd and Boden [2021] EWCA Crim 618.

98 BGH StV 1985, 229; see also BGH NStZ 2000, 414.

99 BGH 2 StR 260/87.

100 See L. Greco, "Kausalitäts- und Zurechnungsfragen bei unechten Unterlassungsdelikten" [2011] Zeitschrift für Internationale Strafrechtsdogmatik 674, 680. 
(hence in a different location). Had the doctor sent his patient for radiation treatment, "the treatment would presumably have killed many cancer cells, somewhat delaying the occurrence of death", even if the patient had not been cured by it. ${ }^{101}$ Apart from appearing to strain the facts of the second case somewhat, the problem with this line of argument is that it seems to miss why we care about what $\mathrm{D}$ failed to do. We care about it because what he failed to do may well have saved V, had he done it: the wife's death is different, not because it occurs in hospital rather than at home, but because - had she been taken to the hospital - it would have occurred (if it had still occurred) only after every effort had been made by medical staff to save her life. The patient's death is different because she is now beyond cure when she might not have been - and not because the progression of her disease would have been slightly delayed even if the treatment had ultimately remained ineffectual. ${ }^{102}$ It is therefore unavoidable for criminal law to face up to the question whether it should let "loss of a chance" suffice for finding causation in some omissions cases, and (if so) which cases these should be. ${ }^{103}$

It is possible to present such cases as essentially raising an evidential issue: whether the finding that an omission was causal for a particular result can justifiably be based on less than practical certainty that the result would have been averted by the performance of the omitted act. ${ }^{104}$ In the German discussion, however, scholars who maintain that it should be sufficient for causal responsibility-attribution to the omitter that the omission can be shown to have had the effect that the victim was exposed to a (substantially) higher risk of the result occurring than she would have been, had the omitter performed the required act, usually present this solution not so much as a lowering of the evidential bar for a finding that the outcome would have been averted than as a shifting of the evidential target, thus in substance as a different legal criterion of responsibility-attribution for results in omissions cases compared to commission cases. ${ }^{105}$

The main argument in favour is one of moral equivalence: What $\mathrm{D}$ failed to do, did make a difference to V's situation in that D's inactivity cost V her

101 Ibid., at 681 .

102 A similar objection is raised by B. Schünemann (quoted in Greco, "Kausalitäts- und Zurechnungsfragen", 680, at footnote 65): the purpose of the imposition of a duty to rescue is not that the circumstances attending the occurrence of the harm are different but that the harm is prevented.

103 This has been defended by many tort lawyers but the courts are still reluctant to accept that compensation can be awarded in many "loss of a chance" scenarios. For an argument that compensation may be compatible with ordinary causation principles, based on a "substantial factor" test, see E. Weinrib, "A Step Forward in Factual Causation" (1975) 38 M.L.R. 518.

104 This appears to be the court's approach in Broughton.

105 This is the so-called "risk-reduction-theory", which functions in the context of omissions as a replacement for causal attributions based on the "result-avoidance-theory" (see Greco, "Kausalitäts- und Zurechnungsfragen", 675-76, 679). Of particular interest in the present context are authors who adopt risk-reduction for omissions but accept standard causation requirements in active causation. There are other authors who argue that causation should be dropped completely as a conceptual category and replaced with risk-increase-based responsibility-attribution throughout. 
best chance of survival in the circumstances. This seems, on an evaluative level, no smaller contribution to V's peril than that made by active conduct which is one of a number of factors that play a role in bringing about the harm $\mathrm{V}$ suffers. $\mathrm{V}$ lost out on receiving the treatment. That much we know. We also know that, statistically speaking, this made her death far more likely than it would otherwise have been. On an evaluative level, we therefore have no real doubt that D's inactivity made things worse for $\mathrm{V}$ because it deprived her of the only thing that could have increased her chances of survival: timely medical help.

To see why we might want to accept this as creating a causal connection, consider a parallel problem that exists in respect of the contribution made by a secondary party to the principal's offence in cases where the secondary party's contribution appears, in retrospect, to have been superfluous or even unhelpful. In this context, I have drawn on Lepora and Goodin's analysis of the appropriate connection in terms of "definitively essential or potentially essential" contributory actions by S to P's wrong ${ }^{106}$ to explain how the wrongness of the secondary party's crime in part resides in its connection to what the principal has done:

What they mean by this is that (from a forward-looking perspective) S's actions serve to make P's venture more likely to occur or to succeed, even though in retrospect they may have been unnecessary, superfluous or unhelpful. S's actions make the venture more secure in this way because (in worlds very close to the actual world, in which S's contribution was unnecessary) his contribution would have been essential for the success of the venture. Lepora and Goodin's way of unpacking causal potency thus avoids collapsing this notion into risk and allows us to link S's earlier behavior to P's crime such that S's wrong is, at that later stage, no longer merely the wrong of an inchoate crime. ${ }^{107}$

If we accept the moral case for treating an omission that cost $\mathrm{V}$ a good chance of survival as causal for V's death, we, however, face a further evidential point: when and on what factual basis can we be sufficiently certain that $\mathrm{V}$ lost a chance? These evidential issues relating to proof of loss of a chance to the criminal standard of proof ("beyond reasonable doubt") were not addressed in Broughton, because the court did not accept as a matter of law that the jury would be entitled to find causation if they were sure that $V$ lost a 90 per cent chance of survival. But if the court had accepted that the loss of such a massive chance of survival is, in legal terms, enough for a jury to find that D's failure to provide $\mathrm{V}$ with that chance was a cause of her death, the next question that would have raised its head was whether the expert evidence in Broughton enabled the jury to be sure of the loss of a 90 per cent chance. Much then seems to depend on the framing of

106 C. Lepora and R.E. Goodin, On Complicity and Compromise (Oxford 2013), 63.

107 Du Bois-Pedain, "Complicity", 203. 
the evidence. Did V in Broughton have "a 90 per cent chance of survival" if the medical experts in that case were only 90 per cent sure that the treatment she would have received works when this particular drug has been ingested? Or would this have meant that it was not established beyond reasonable doubt that $\mathrm{V}$ had any chance at all? If the latter, how, if at all, would this differ from cases where expert evidence states that "this treatment works against this condition for 9 out of 10 patients"? In the latter case, it would appear certain that V lost a 90 per cent chance of survival. But if one were to dig deeper into the question why the treatment does not help one out of 10 patients, might we not find medical explanations that show that these patients' cases were "lost causes" even before the treatment was given? In which case, wouldn't this also be a case where there is a 10 per cent possibility that $\mathrm{V}$ was beyond saving anyway?

These issues would have to be thought through carefully before the criminal law goes down the route of lowering the evidential bar (to some degree of probability less than practical certainty), and/or of choosing a different evidential target ("proven increase of risk", "proven loss of a chance"), and thus effectively of creating a different legal test for causal responsibility-attribution in omissions cases. This is not the place to resolve these questions - only to mark their status as relevant and as-yet-unresolved questions for causation by omission.

\section{CONCLUSION}

Williams concluded his article by providing a draft clause on causation for a future Criminal Code. ${ }^{108}$ Many other authors have followed him in this endeavour. ${ }^{109}$ It should be clear by now why I will not go down this road. The principles of legal causation (such as they are) are meant to aid us in arriving at a judgment of causal responsibility-attribution. But they function as "topoi" (i.e. themes, aspects to be considered) rather than as rules to be followed. Moreover, most of the considerations they invite us to have regard to, refer to scalar properties. A "freaky causal chain" can be more or less freaky, another agent's reaction more or less expectable. As Feinberg perceptively wrote, "after the facts are in, we do not have complete license to settle the attributive question in accordance with our moral standards, policies, and purposes, [in that] certain commonsense principles here place effective limits on our discretion". ${ }^{110}$ But to try and pin down the limits on our ability to attribute causal responsibility to "the person or entity who we believe deserves to be held responsible" through a formulation of abstract rules, to be strictly applied, is a fool's

\footnotetext{
108 Williams, "Finis", 414-16.

109 See e.g. Yeo, "Blamable Causation”, 162; P.H. Robinson, “The Model Penal Code's Conceptual Error on the Nature of Proximate Cause, and How to Fix it" (2015) 51 Criminal Law Bulletin 1311, 1316.

110 Feinberg, "Causing Voluntary Actions", 184.
} 
errand. The two-pronged attributive judgment that needs to be made (the first prong attributing the occurrence of an outcome to an instance of human conduct, the second one attributing responsibility for the occurrence of that outcome to the human agent who performed the conduct) is highly sensitive to the precise factual constellation and the interrelation of different contributing factors. Causation thus may be one of the few areas where the common law's traditional resistance to abstraction and generalisation has a legitimate place. 